\title{
A Rare Differential Diagnosis of Crazy Paving Pattern
}

Sir,

The "crazy-paving pattern" is scattered or diffuse ground glass attenuation with superimposed interlobular septal thickening and intralobular lines. Crazy-paving pattern initially was pathognomonic sign of pulmonary alveolar proteinosis. In the recent era, there are number of acute and chronic conditions described for crazy paving pattern. The crazy-paving pattern on computed tomography (CT) is a nonspecific finding. The pattern is formed by superimposition of interlobular and intralobular thickening on ground-glass opacity on CT, resembling the structure of irregularly shaped paving stones. $^{[1]}$ Most diseases are usually diagnosed based on clinicoradiological findings and in few cases biopsy with histopathological examination is needed to establish the etiological diagnosis.

A 42-year-old female reported to our department with complaints of cough with expectoration which was nonpurulent, diffuse chest pain, dyspnea, and off and on minimal hemoptysis since the past 9 months. She also had weight loss since 7 months. She was an ex-smoker and nonalcoholic and was on anti-tubercular treatment for 4 months without any improvement.

Her general physical examination was within normal limits. Respiratory examination revealed bilateral scattered wheeze and crackles. Blood investigations were not significant, and her serology was nonreactive. Chest radiograph revealed reticular nodular lesions more in upper and mid zones [Figure 1]. Sputum smear was negative for acid-fast bacilli (AFB), gram staining and culture were sterile. Sputum culture for mycobacteria was also negative. Contrast-enhanced CT (CECT) chest was done which revealed evidence of conglomerated areas of alveolar filling

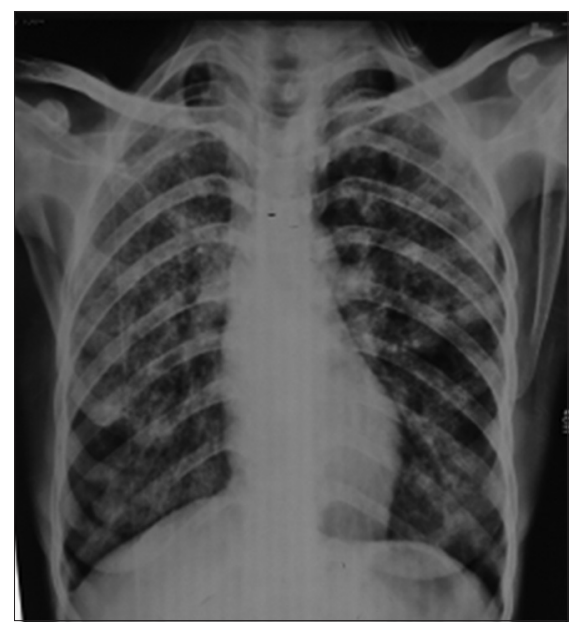

Figure 1: Chest radiograph revealed reticular nodular lesions more in upper and mid zones predominantly involving bilateral upper lobe and superior segment of bilateral lower lobes the crazy paving pattern more in favor of pulmonary alveolar proteinosis [Figure 2]. Fiberoptic bronchoscopy was done which did not show any intraluminal growth. Bronchoalveolar lavage and transbronchial lung biopsy were performed from involved segments, and specimen was sent for AFB smear, malignant cytology, and periodic acid-Schiff staining. Bronchoalveolar lavage came to be inconclusive, while histopathology report revealed: alveolar spaces lined by well-differentiated mucin containing columnar cells, the cells also in bronchiolar lining suggestive of mucinous adenocarcinoma [Figure 3]. The patient, in this case, was not a candidate for surgery as he had multifocal disease. Chemotherapy was offered in a combination of carboplatin and paclitaxel. Three cycles of chemotherapy were given to the patient, but she expired after completion of the third cycle. Initially, crazy-paving pattern was considered to be highly suggestive of pulmonary alveolar proteinosis. ${ }^{[2]}$ Nowadays, this pattern is found in different lung conditions such as pulmonary edema, Pneumocystis jiroveci pneumonia, pulmonary hemorrhage, acute interstitial pneumonia, acute respiratory distress syndrome, radiation pneumonitis, pulmonary alveolar proteinosis, organizing pneumonia, subacute and chronic hypersensitivity pneumonitis, Churg-Strauss syndrome, lymphangitic spread of tumor, chronic eosinophilic pneumonia, and bronchioloalveolar carcinoma (BAC). ${ }^{[3-5]}$ The crazy-paving pattern consists of scattered or diffuse ground-glass attenuation with superimposition of a linear pattern. These lines can be: thickened interlobular septa (septal lines), thickened intralobular septa, and thickening of the

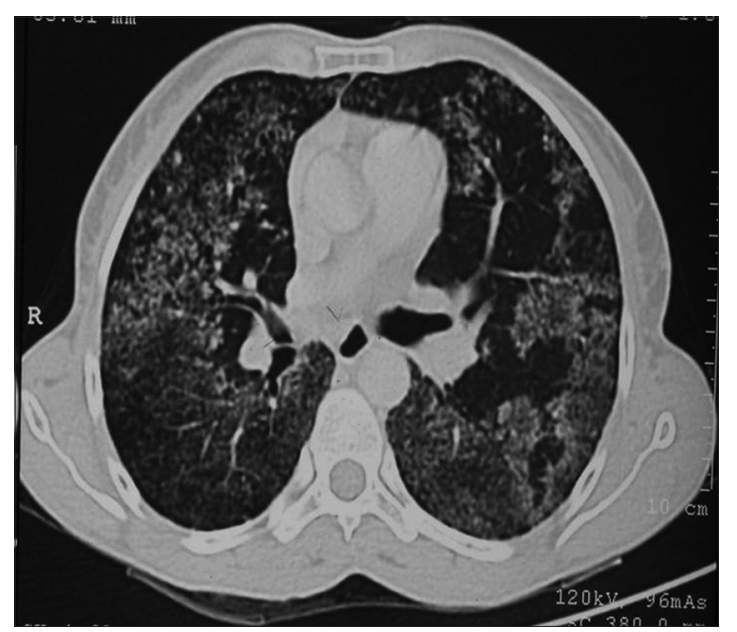

Figure 2: Contrast-enhanced computed tomography chest showing evidence of conglomerated areas of alveolar filling predominantly involving bilateral upper lobe and superior segment of bilateral lower lobes - the crazy paving pattern 


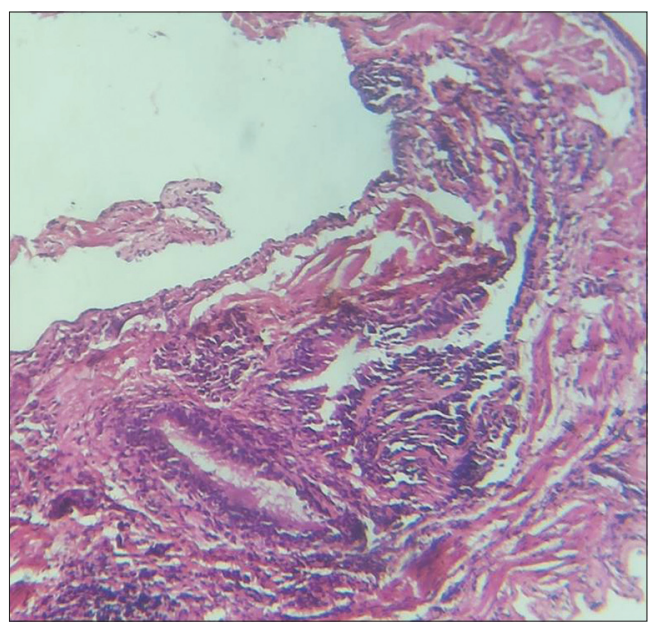

Figure 3: Transbronchial lung biopsy revealed: Alveolar spaces lined by well-differentiated mucin containing columnar cells, the cells also in bronchiolar lining suggestive of mucinous adenocarcinoma

intralobular interstitium (intralobular reticular pattern and intralobular branching lines), or it can be a linear deposition of material within the airspaces at the borders of the acini and the secondary pulmonary lobules (periacinar pattern). ${ }^{[1,6,7]}$ BAC presenting radiologically as a crazy-paving pattern is a distinct rarity. ${ }^{[8]} \mathrm{BAC}$ should always be considered in the differential diagnosis of this singularly unusual HRCT imaging pattern.

BAC may present with a variety of CT appearances such as the CT angiogram sign or air bronchograms in solitary nodules and the periphery of larger consolidations, unifocal or multifocal ground-glass opacities and lobar or multilobar consolidation and cavitating nodules and crazy paving. ${ }^{[9]}$ The definite treatment is surgical, offered to patients with Stage I/II disease. Patients with multifocal disease can only be given chemotherapy which has a poor response in BAC.

\section{Declaration of patient consent}

The authors certify that they have obtained all appropriate patient consent forms. In the form the patient(s) has/have given his/her/their consent for his/her/their images and other clinical information to be reported in the journal. The patients understand that their names and initials will not be published and due efforts will be made to conceal their identity, but anonymity cannot be guaranteed.

Financial support and sponsorship

Nil.

\section{Conflicts of interest}

There are no conflicts of interest.
Govind Singh Rajawat, Aashish Kumar Singh, Thomas Kurian, Suresh Koolwal

Department of Respiratory Medicine, Institute of Respiratory Diseases, SMS Medical College, Jaipur, Rajasthan, India

Address for correspondence: Dr. Aashish Kumar Singh, A13B Ram Marg, Vijay Path, Tilak Nagar, Jaipur, Rajasthan, India. E-mail: singhaashish@yahoo.com

\section{References}

1. Lee CH. The crazy-paving sign. Radiology 2007;243:905-6.

2. Murch CR, Carr DH. Computed tomography appearances of pulmonary alveolar proteinosis. Clin Radiol 1989;40:240-3.

3. Akata S, Park J, Shindo H, Yoshimura M, Kakizaki D, Abe K, et al. Barium aspiration showing crazy-paving appearance on high-resolution computed tomography. Australasian Radiology 2007;51 Suppl. Doi:10.1111/j.1440-1673.2007.01757.

4. da Silva Filho FP, Marchiori E, Valiante PM, Escuissato DL, Gasparetto TD. AIDS-related Kaposi sarcoma of the lung presenting with a "crazy-paving" pattern on high-resolution CT: Imaging and pathologic findings. J Thorac Imaging 2008;23:135-7.

5. Johkoh T, Itoh H, Müller NL, Ichikado K, Nakamura H, Ikezoe J, et al. Crazy-paving appearance at thin-section CT: Spectrum of disease and pathologic findings. Radiology 1999;211:155-60.

6. Rossi SE, Erasmus JJ, Volpacchio M, Franquet T, Castiglioni T, McAdams HP, et al. "Crazy-paving" pattern at thin-section CT of the lungs: Radiologic-pathologic overview. Radiographics 2003;23:1509-19.

7. Hansell DM, Bankier AA, MacMahon H, McLoud TC, Müller NL, Remy J, et al. Fleischner society: Glossary of terms for thoracic imaging. Radiology 2008;246:697-722.

8. Tan RT, Kuzo RS. High-resolution CT findings of mucinous bronchioloalveolar carcinoma: A case of pseudopulmonary alveolar proteinosis. AJR Am J Roentgenol 1997;168:99-100.

9. Patsios D, Roberts HC, Paul NS, Chung T, Herman SJ, Pereira A, et al. Pictorial review of the many faces of bronchioloalveolar cell carcinoma. Br J Radiol 2007;80:1015-23.

This is an open access journal, and articles are distributed under the terms of the Creative Commons Attribution-Non Commercial-ShareAlike 4.0 License, which allows others to remix, tweak, and build upon the work non-commercially, as long as appropriate credit is given and the new creations are licensed under the identical terms.

\begin{tabular}{|l|l|}
\hline \multicolumn{2}{|c|}{ Access this article online } \\
\hline Quick Response Code: & Website: \\
& www.ijmpo.org \\
\cline { 2 - 2 } & DOI: \\
\hline
\end{tabular}

How to cite this article: Rajawat GS, Singh AK, Kurian T, Koolwal S. A rare differential diagnosis of crazy paving pattern. Indian J Med Paediatr Oncol 2018;39:415-6.

○ 2018 Indian Journal of Medical and Paediatric Oncology | Published by Wolters Kluwer - Medknow 